\title{
IMPACT OF STORAGE CONDITIONS ON BIODETERIORATION OF ANCIENT EGYPTIAN CHILD MUMMIES BY XEROPHILIC FUNGI
}

\author{
Mansour, M. \\ Conservation dept., Faculty of Archaeology, Cairo Univ., Giza, Egypt \\ E-mail:maisamansour_40@yahoo.com
}

\begin{abstract}
The study was conducted on a child's mummy aged 6 to 8 years, with a damaged skull. It was found in Dahshur, Egypt. 10 fungal species were isolated and identified. Fungi have been determined by PCR amplification and sequencing as follows: Cladosporium cladosporioides (LC325159), Penicillium chrysogenum (LC325162) and Aspergillus flavus (LC325160). Modern linen samples were inoculated and incubated by the isolated fungi for a period of three months. Fungi decay results were assessed using Energy Dispersive $X$-Ray Spectrometry (EDX) and $X$ Ray Diffraction (XRD). It was evident that $\mathrm{NaCl}(100 \%)$ have been used in the mummification process and the three identified fungi could grow on linen even under high saline ( $\mathrm{NaCl})$ conditions. $\underline{\text { C. }}$ cladosporioides showed a considerable increment in hyphal production, while $\underline{P}$. chrysogenum hyphae were filled with salt crystals. Growth of $\underline{A}$. flavus covered linen surface, while salt crystals were found in the conidiophores. Xerophilic and Halophilic fungi grown and caused decay of the mummy located in the burial chamber.
\end{abstract}

Keywords: Xerophilic fungi, Growth, Environmental, Salt, Mummy.

\section{Introduction}

It's known that dry environmental conditions are the key factors for long lasting preservation of ancient Egyptian mummies, the combination of evisceration, desiccation with powdered natron and hot, liquid resin were believed to discourage microbial growth and prevent re-hydration as initiated during the old kingdom [1-6]. However, low moisture content and high salt concentrations, with the existence of other organic materials, are probably the cause of severe fungal colonization on the mummies in the storage conditions in the "burial chamber". Otherwise, the environmental conditions prior to the excavation of the mummy, i.e., water flooding of the burial site, could have caused deterioration. Poor display or storage conditions after digging could be blamed for the deterioration. High relative humidity, inadequate air circulation, and darkness provide an ideal environment for fungal growth. Unsuitable environmental conditions can be very destructive for skin tissues, the resin content in the mummy and the linen wrappings [7-10]. Fungi can cause deterioration because of their enzymatic activities and their ability to grow and deform textiles, leather, and other materials [11]. These activities are commonly found in indoor environments on some archaeological organic materials, 
as skin and fabrics in the form of spread scattered spots of mycelial growth [12]. Halo tolerant and halophilic fungi have been known to cause degradation of materials stored at high condensation of salt or sugar (they grew well on substrates with $\mathrm{NaCl}$ or glucose in their growth media [13-18]. These fungi exhibited potential resistance to high temperature and high salt concentration [19,20]. Media modified by supplementing $\mathrm{NaCl}$ was determined even in dry environment. Penicillium species grew on meat at $37.83 \%$ RH and salt concentration 5.07\% [21], while water activity was 0.89 [22]. Xerophilic fungi such as, Eurotium rubrum, E. repens, Wallemia sebi, A. penicillioides, and $P$. roqueforti grew faster under acidic conditions than neutral $\mathrm{pH}$ conditions and at temperatures; 25, 30 and $37{ }^{\circ} \mathrm{C}$ [23]. Specialized microorganisms wellknown for their cellulolytic and proteolytic appeared on textiles and skin. These specialized fungi are menacing the preservation of the mummies [24,25]. $P$. chrysogenum was also found on aromatic compounds in high salinity [26]. Fungi require certain essential nutrients for growth; these nutrients comprise water, nitrogen, vitamins, and minerals $[27,28]$. Meat is a major source of protein, fats and vitamins [29]. Historical textile materials when exposed to high humidity can easily decay due to their chemical composition, such as cellulose [30]. Cellulolytic fungi can feed by mycelial penetration into cellulosic material, leading to the loss of fiber strength [31,32]. Some fungal contamina-

\section{Materials and Methods}

\subsection{Sampling}

The child's mummy in the wooden sarcophagus from Dahshur in Giza, Egypt was selected for this study. Remarkable linen wrappings covered the mummy, while resin was used to coat the fibers. Samples for the study were taken from seriously deteriorated tion can take place at low temperature and relative humidity. This occurred in two fungal species, $P$. chrysogenum and C. cladosporioides $[33,34]$. Contamination was usually characterized by white spots of mycelium, measuring $0.5-1.0 \mathrm{~cm}$ in length on both leather and textiles [35]. Saprophytic fungi such as Penicillium spp., Alternaria spp., A. fumigatus, A. nidulans, Rhizopus spp. and Chrysosporium spp. were isolated from the mummy in one of the Archaeological museums in Zagreb [36]. Earlier studies identified the xerophilic fungi such as E. halophilicum, A. halophilicus, A. versicolor, Cladosporium spp., P.nalgiovense, $P$. milanense, $P$. brevicompactum, $P$. chrysogenum, $P$. nordicum, and $P$. polonicum were isolated from surfaces of dry-cured meat at minimum water content in locked environment [17, 20, 37-39]. Xerophilic fungi such as $A$. versicolor were isolated from gelatin, cellulose, tributyrin, and oils [40]. Therefore, they can be considered as an extremely important factor of the deterioration of mummies. Xerophilic fungus can also grow on leather or fabric bindings [12]. Some Xerophiles and halophilic fungi can help in the degradation of the mummy, because of its ability to grow on dry meat with high level of salinity. In addition, it can grow in closed areas. Thus, fungi have been isolated from the linen wrappings touching mummy skin. This case was isolated to help in the identification of fungal degradation of the child's mummy by ITS sequencing.

areas (from the wrapping section in contact with the mummy skin). Four samples were taken from the mummy's linen fragments showing signs of deterioration, fig. (1). Samples codes were byn1, byn2, byn 3 and bny 4 . The samples were then stored at $4^{\circ} \mathrm{C}$. 


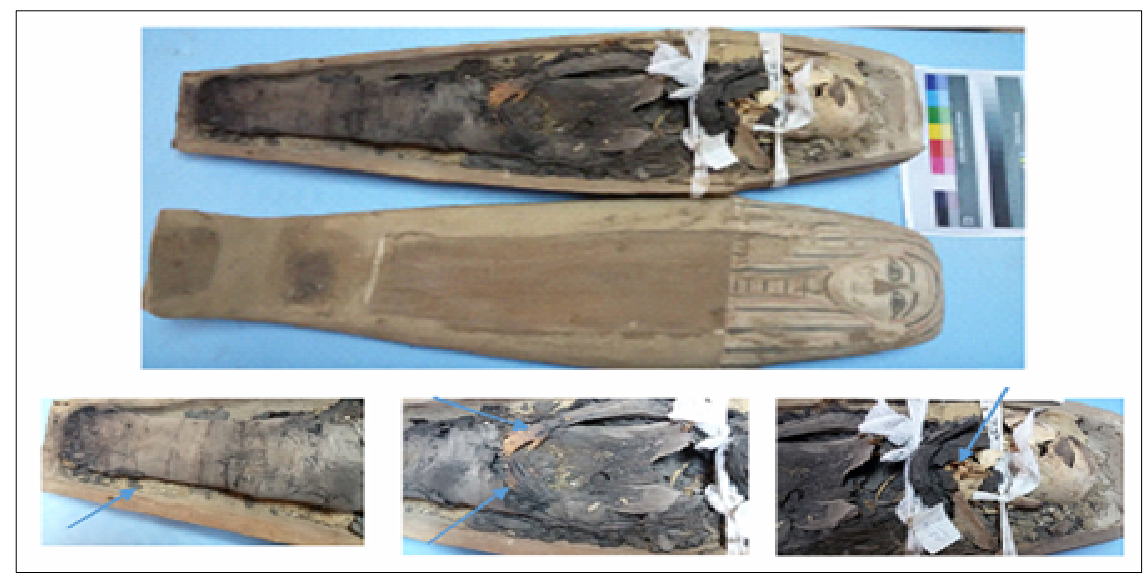

Figure (1) Shows samples were collected from different places of the mummy surface

\subsection{EDX-SEM and XRD analysis}

EDX analysis unit accompanied by scanning electron microscopy model-a FEI Quanta 200 SEM FEG was used to study the textile wrappings of the mummy and colonization of linen surface by microorganisms. Furthermore, the band positions

\subsection{Identification of fungi by ITS sequ
Isolating fungi from the wrappings} were directly performed in vitro after swabbing. The fungi were isolated by gentle rubbing with swabs on different culture media. The media comprised the following: 1) M40Y; 2) potato-dextrose agar (PDA with $5 \% \mathrm{NaCl})$. Petri dishes were incubated

\subsection{Colonization test}

The linen samples were cut into $(20 \times 20 \mathrm{~mm})$ using a scalpel. Then they were saturated by liquid media which was maintained on Malt extract agar (MEA) with $5 \% \mathrm{NaCl}$ [44].Then the saturated linen was placed on the glass slide in a sterilized Petri dish. Spores suspensions from C. cladosporioides, P. chrysogenum

\section{Results}

\subsection{EDX-SEM and XRD results}

According to EDX micro-analysis, the linen was affected by fungi, where, $\mathrm{C}$ percentage was $(22.97 \%)$, the $\mathrm{Ca}$ $(0.21 \%)$, the $\mathrm{Fe}(0.05 \%)$ the $\mathrm{N}$ content found in wrapping linen $(3.12 \%)$, and the $\mathrm{Si}(0.13 \%)$, while minor elements, $\mathrm{S}$ $(0.36 \%)$, and trace elements are $\mathrm{Cu}$ of crystalline and amorphous regions of cellulose forms of deteriorated and standard linen samples were measured by using Philips Analytical X-Ray B.V.; while the crystallinity index (CI) was calculated according to a pro-posed method [41]. at $25 \pm 2{ }^{\circ} \mathrm{C}$ for five days. Identification of the isolated fungi was done on the bases of PCR and ITS [42,43]. The PCR products of ITS $5.8 \mathrm{~S}$ and D1/D2 28S rRNA domains were directly sequenced in a Hitachi 2120 Genetic Anal-yzer (Applied Biosystems GenBank in Japan).

and A. flavus grown in monitored environment by MEA with 5\% salt were used to inoculate the linen. Linen fibers were investigated before and after infection. The pathogenic test was under taken after three months' period. The colonization patters were done using SEM-EDAX analysis $[45,46]$.

$(0.05 \%) \mathrm{Zn}(0.06 \%)$ were also found in the wrapped linen. Na content $(1.16 \%)$ and $\mathrm{Cl} 0.43 \%$ ) tab. (1), fig. (2-a) which indicate $\mathrm{NaCl}$ being used in the mummification process. The results give important evidence for Egyptologists about the utilizing of sodium chloride 
salt in the method of embalming. In addition it could be toned through XRD pattern, fig. (2-b) that the salt disfigured a portion of the linen and indicated the existence of $\mathrm{NaCl}(100 \%)$. SEM examination indicated that the textile wrappings of the mummy are likely made of flax. The textile sample composed only of brown fiber threads in an open plain weave, fig. (3-a,b,c,d). This shows that those nodes with flax fibers and their distinctive "bamboo-like" shape, which appeared under the scanning electron microscope, identified the textile as linen, (biod-egraded linen in a burial soil).

Table (1) EDX analysis results of wrapping linen deterioration by fungi

\begin{tabular}{rcccccccccc}
\hline Element & $\mathbf{C}$ & $\mathbf{N}$ & $\mathbf{N a}$ & $\mathbf{S i}$ & $\mathbf{S}$ & $\mathbf{C l}$ & $\mathbf{C a}$ & $\mathbf{F e}$ & $\mathbf{C u}$ & $\mathbf{Z n}$ \\
\hline Weight \% & 22.97 & 3.12 & 1.16 & 0.13 & 0.36 & 0.43 & 0.21 & 0.05 & 0.05 & 0.06 \\
\hline
\end{tabular}
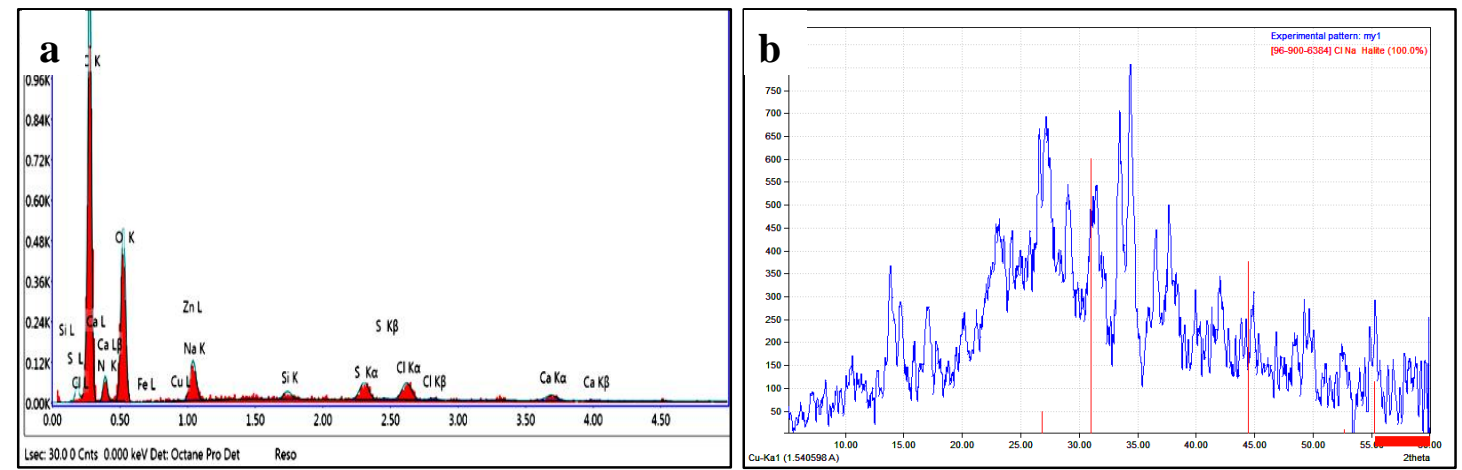

Figure (2) Shows $\underline{\mathbf{a}}$. XRD pattern of salt on linen, $\underline{\mathbf{b}}$. EDX results of the linen surface elements, expressed in mass percentages (wt \%)
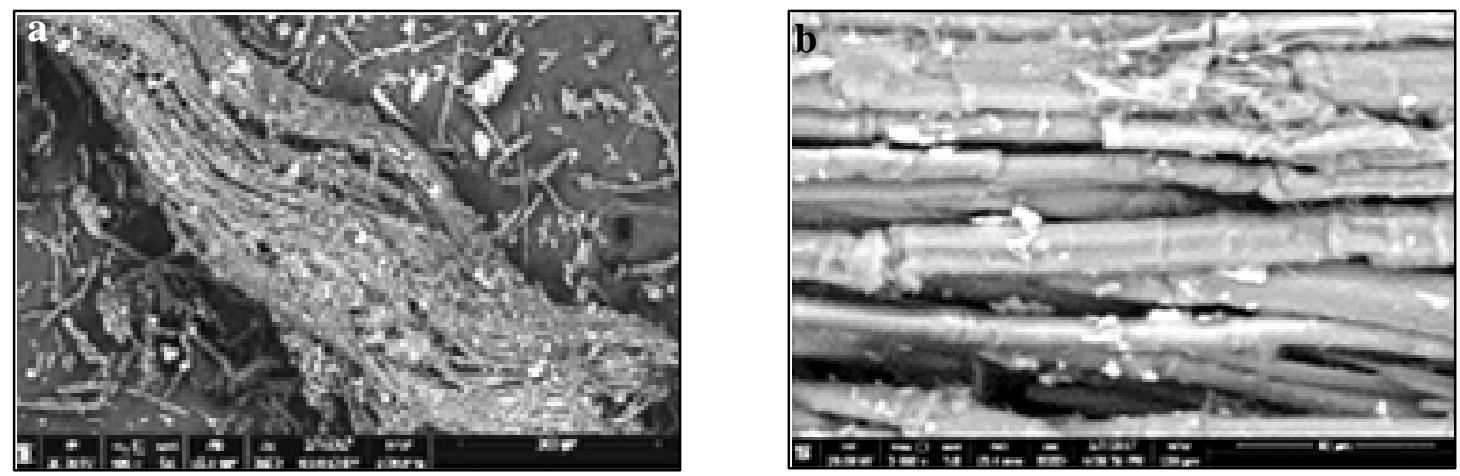

Figure (3) Shows SEM image a. orientation of fibers in the S-twist or counter-clockwise orientation linen fibers, $\underline{\mathbf{b}}$. degradation of linen fibers happened after along-term of being in the burial chamber, which affected the composition of the linen fabric. Linen separated as the fibers are not tightly twisted

\subsection{Identification of fungi by ITS sequencing}

The sequencing confirmed the identity of the isolates as $C$. cladosporioides, $P$. chrysogenum and A. flavus with $99 \%$ similarity to GenBank under the access numbers of LC325159, LC325162 and LC325160, respectively. The C. cladosporioides (GenBank accession No. LC325159) was one of the largest genera characterized by a coronate scar structure, conidia in acropetally chains and Davidiella teleomorphs. Based on morphology and DNA phylogeny, fig. (4), pertinence to the $C$. cladosporioides complex were exa- mined and phylogenetically analyzed on the basis of DNA sequences of the nuclear ribosomal RNA gene operon/PCR_primers= "fwd_seq: CGTAGGTGAACCTGCGG, rev_seq: CCTCCGCTTATTGATATGC", $P$. chrysogenum $\mathrm{LC} 325162 / \mathrm{PCR}$ _ primers= "fwd_seq: TCCGTAGGTGAACCTGCGG, rev_seq: TCCTCCGCTTATTGATATGC and Aspergillus flavus LC 325160PCR primers="fwd_seq: TCCGTAGGTGAACCTGCGG, rev_seq: TCC TCCGCTTATTGATATGC, Including the internal transcribed spacer regions ITES 1 and ITES 4. 


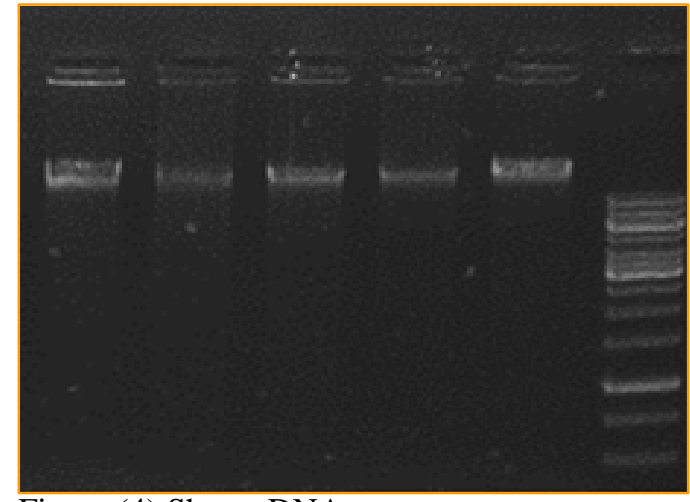

Figure (4) Shows DNA sequences

\subsection{Colonization test results}

Infected linen saturated by liquid media on Malt extract agar (MEA) with $5 \% \mathrm{NaCl}$ by fungi (C. cladosporioides, $P$. chrysogenum and A. flavus) was incubated for three months. Most of the compounds of the mummy provide fungi with the major components needed for their growth. The infected wrapping was examined by SEM for mycelia growth as shown in the SEM image (5-a). The control sample of linen saturated by (MEA) and $5 \% \mathrm{NaCl}$ and without infection by fungi is shown in fig. (5-b). C. cladosporioides scan grow on linen surface, within the fibers and separate the fibers. C. cladosporioides was considered to be xerophilic, which can grow on MEA added to the linen and salt causing a considerable increase in hyphal production and spores. Salt crystals were observed in the hyphae and conidial production shown by SEM fig. (5-c,d) SEM micrographs show the morphology of P. chrysogenum (GenBank access No. LC325162), fig. (5-e,f). The round structures seen here are conidia. Each chain of conidia grows on a specialized hypha known as a conidiophore

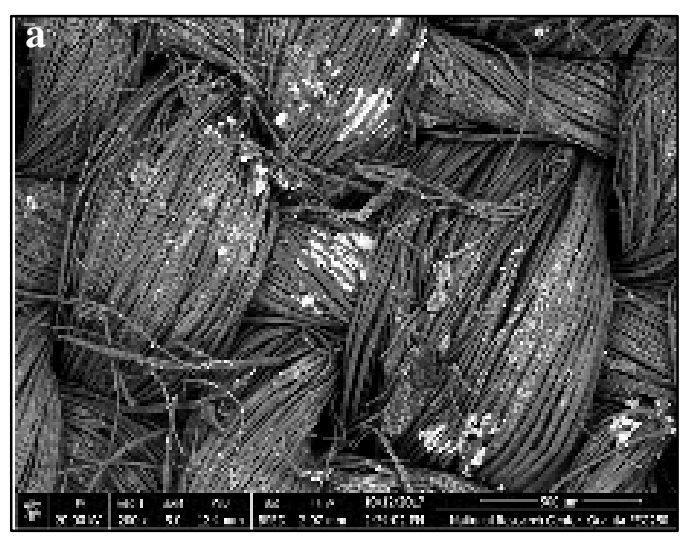

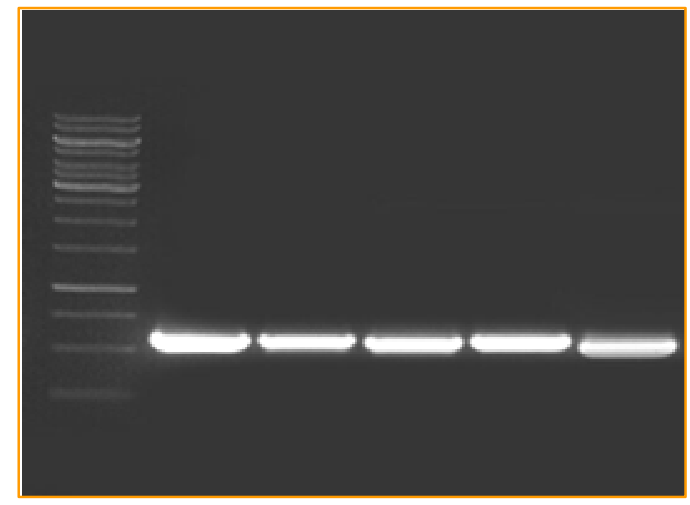

and the hyphal tips were smooth and chained. The halotolerance of $P$. chrysogenum has grown on $5 \% \mathrm{NaCl}$ concentration. The hyphae is filled with salt crystals, fig. (5-e,f) as a result of the application of wrapping, a significant increase in hyphal production and spores occurred. So color changed into dark green. $P$. chrysogenum can grown the mummy and its degradation results in the availability of dry meat, salt and aromatic compounds. Growth was clearly shown by SEM, fig. (5-e,f). SEM appearance of A. flavus LC325160 conidial head and round-shaped vesicles with yellow to brown mold colonies. A. flavus application on linen with salt caused a significant increase in the production of hyphae and spores on the linen tested, in addition to changing the color of the linen to black green. However, these observations indicate that the conidial production of the A. flavus might increase on linen, the salt crystals appeared in the conidiophores. Salt crystals were clearly shown in SEM fig. (5-g,h).

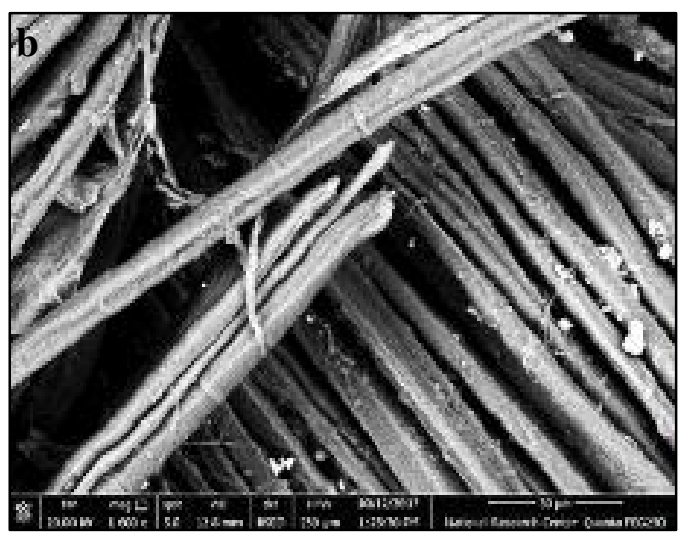



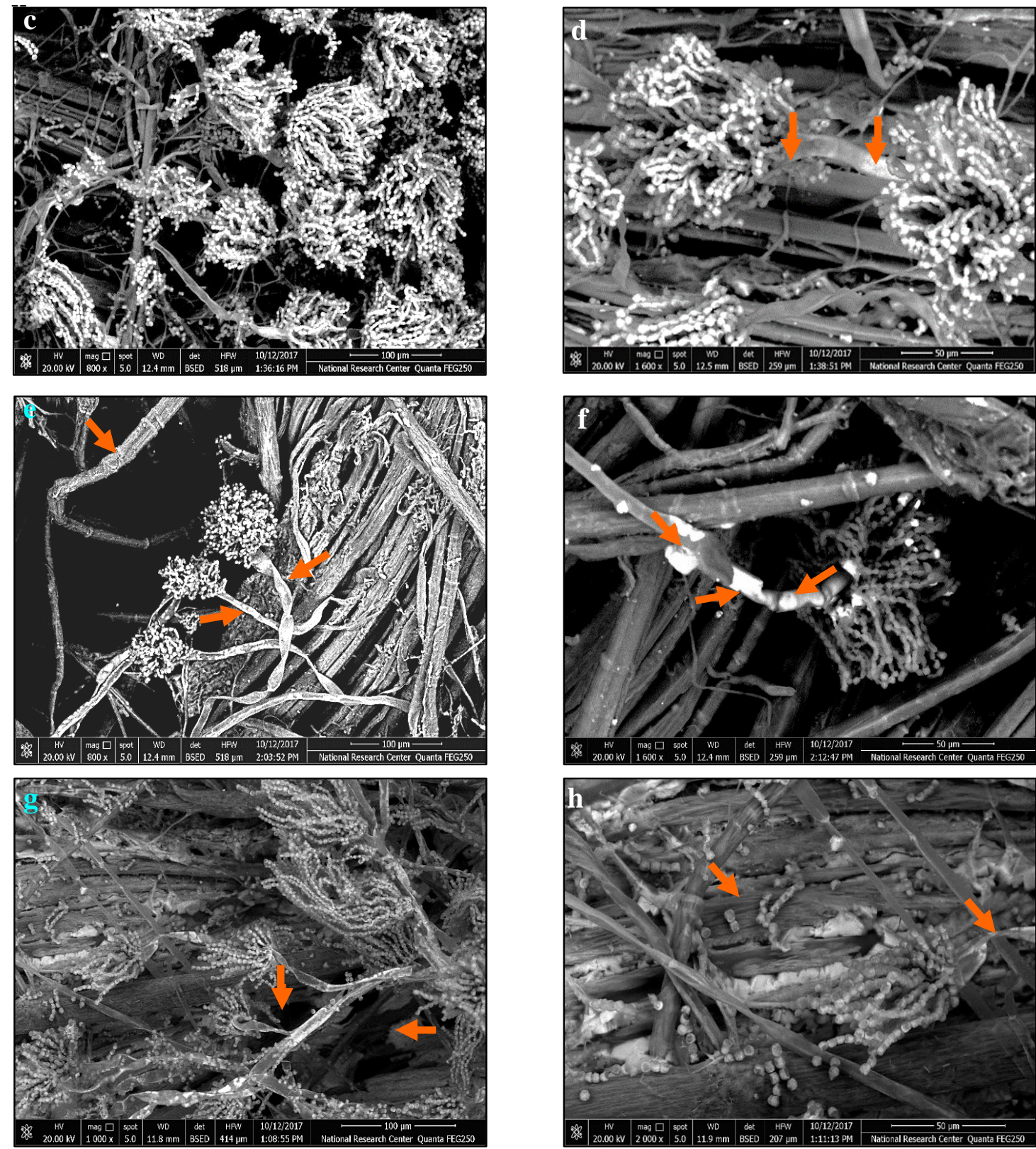

Figure (5) Shows $\underline{\mathbf{a}}$. the infected wrapping, $\underline{\mathbf{b}}$. the control sample (linen saturated by liquid media on Malt extract agar (MEA) with $5 \%(\mathrm{NaCl})$, ‥, $\underline{\text { d. }}$. Cladosporium cladosporioides LC325159 growth on the linen, e. . f. Penicillium chrysogenum LC325162 growth on the linen, g., $\underline{\mathbf{h}}$. Aspergillus flavus LC325160 growth on the linen

\section{Discussion}

SEM was able to show the morphology of fiber and fabric surfaces, because of the irregular nodes [47]. Microorganisms are responsible for the biodeterioration of fibers (as SEM clarified) [48]. Microorganism decay is one of the most important factors of deterioration of linen materials; natural fibers have a high content of cellulose, a nutrient for most of microorganisms considered the most serious for fiber. The mummy's suscep- tibility to deterioration depends on chemical composition of mummification materials (salt, linen, oil and resin) [11], as well the environmental factors like humidity, $\mathrm{pH}$, light and temperature $[33,34]$. The deterioration in the cavity of the fiber caused by fungi also showing increased damage of fiber and swelling. The linen fiber contained a coarse material, proving the deterioration of the linen, also spore and hyphae growing within 
fiber cells and inside was noted in fig. (3), so the occurrence of cavity holes and cracks in fiber caused by the fungi and hyphae inside the fibers, while the resin can be observed as a layer too $[31,32,49,50]$. The author specified a new genomic aim sequence existing in the single copy gene for tRNA nucleotidy transferase directly to the requirements for a ubiquitous, yet highly specific DNA marker [51-53]. Some fungal contamination can take place even at low temperature and moisture. This was true in the condition of two fungal species, $P$. chrysogenum and $C$. cladosporioides [33,34]. $P$. chrysogenum growth on aromatic compounds in high salinity was evident[26]. Identified fungi isolated from soil salt marshes in Egypt. The most recurrent fungi were Aspergillus sp., Cladosporium sp. and Penicillium sp.[54] $P$. chrysogenum was isolated from a burial chamber in Upper Egypt the strains grown in a least salts in vitro
[55]. Cladosporium spp., isolated from surface of dry-cured meat products [37]. The C. cladosporioides halophilic and halo-tolerant can grow on the salt and can be characterized by their nearly spherical shape [56]. The monitoring suggests that the conidial production of $P$. chrysogenum may increase at high salinity with growth, being more active as salt concentration rise [57]. Halotolerant fungal $P$. chrysogenum isolated from the salty-water can grow in $15 \% \mathrm{NaCl}$ [58], and in this case growing on dry-cured meat $[37,22]$. $P$. chrysogenumwas was able to degrade aromatic compounds in high salinity [26]. The conidiophores of Aspergillus sp are variable in length [59]. The Aspergillus sp. can grow on salt crystals, where the growth increase with salt concentration rise [58]. $P$. chrysogenum and $C$. cladosporioides were important protein and lipid activities [60].

\section{Conclusion}

Mummies represent an important and significant part of the Egyptian and the global cultural heritage. They can be considered as complex objects made mostly of mummified, linen, salt and essential oils. The variety of materials used and environmental factors have a significant impact on their infection by xerophiles fungi. Therefore, they are expected to be isolated from the mummy and wrappings, which prefer growth in indoor places. Xerophiles (osmophiles) and halophilic fungi share together the credit for degradation to the mummy because xerophiles can grow on dry meat, halophilic fungi can also tolerate high salinity, grown in similar environment conditions. In this study, Xerophiles fungi (Cladosporium cladosporioides, Penicillium chrysogenum and Aspergillus flavus) is presented in indoor environmental and for identification of individual genotypes. In addition, these fungi can produce mycotoxin that may also affect human health by breathing the high concentration of aflatoxins and fungal spore, when opening the burial chamber after its one thousand years of being closed.

\section{Acknowledgments}

The author would like to thank Prof. Hiroshi Suita, Director of $\mathrm{CHC}$, Kansai Univ. My appreciation also goes to Dr. Mohamed Z.M. Salem of the Forestry and Wood Technology Department, Faculty of Agriculture (EL-Shatby), Alexandria University, Alexandria, Egypt.

\section{References}

[1] Rullkötter, J. \& Nissenbaum, A., (1988). Dead Sea asphalt in Egyptian mummies: molecular evidence. Naturwissenschaften, Vol. 75, pp: 618-621.

[2] Aufderheide, A., (2003). The scientific study of mummies, Cambridge Univ. press, UK.
[3] Abdel-Maksoud, G. \& El-Amin, A., (2011). A review on the materials used during the mummification processes in ancient, MAA, Vol. 11 (2), pp: 129150.

[4] Jones, J., Higham, T., Oldfield, R., O'Connor, T. \& Buckley, S., (2014). 
Evidence for prehistoric origins of Egyptian mummification in late Neolithic burials, PLOS ONE 9(8): doi:10.1371/ journal.pone.0103608

[5] Brettell, R., Martin, W., AthertonWoolham, S., Stern, B. \& McKnight, L., (2017). Organic residue analysis of Egyptian votive mummies and their research potential. Studies in Conservation, Vol. 62, pp: 68-82.

[6] Isidro, A. \& Herrerin, J., (2017). Meningeal preservation in a child mummy from ancient Egypt. World Neurosurg, Vol.100, pp: 579-582.

[7] David, A., (1986). Conservation of mummified Egyptian remains, in Bard, K. (ed.) Proceedings of the Science in Egyptology University of Manchester Symposia. pp. 87-90.

[8] David, A. \& David, A., (1995). Preservation of human mummified specimens, in: Collins, C. (ed.) The Care and Conservation of Palaeontological Material, Butterworth-Heinemann, UK, pp: 73-88.

[9] Khalil, E., (2014). Air flow patterns and thermal behavior in "King Tutankhamen Tomb". Int. J. Heat Mass Transfer-Theory Applications (IREHE $A T)$, Vol. 2 (4), pp: 118-124

[10] Hamdi, A., Ali, M., EL-Bialy, E. \& Khalil, E., (2015). Flow regimes and thermal analyses in ventilated archeological tomb KV57, Valley of the Kings, Luxor. Energy Power Sources, Vol.2, pp: 131-136.

[11] Sterflinger, K., (2010). Fungi: Their role in deterioration of cultural heritage, Fungal Biology Reviews, Vol. 24 (1-2), pp: 47-55.

[12] Micheluz, A., Manente, S., Tigini, V., Prigione, V., Pinzari, F., Ravagnan, G. \& Giovanna Cristina, V., (2015). The extreme environment of a library: Xerophilic fungi inhabiting indoor niches. Int. Biodeterior. Biodegrad, Vol. 99, pp: 1-7.

[13] Pitt, J. \& Hocking, A., (1985). Fungi and food spoilage, in: John, I. (ed.), $2^{\text {nd }}$ ed. Academic Press, Sydney, pp: 517-576.
[14] Andrews, S., Pitt, J., (1987). Further studies on the water relations of Xerophilic fungi, including some halophiles. J. of General Microbiology, Vol. 133, pp: 233-238.

[15] Kogej, T., Ramos, J., Plemenitaš, A. Gunde-Cimerman, N., (2005). Halophilic fungus Hortaeawerneckii and the Halotolerant fungus aureobasidium pollutants maintain low intracellular cation concentrations in hyper saline environments, Appl. Environ. Microbiol., Vol.71, pp: 6600-6605.

[16] Obuekwe, C., Badrudeen, A., AlSaleh, E. \& Mulder, J., (2005). Growth and hydrocarbon degradation by three desert fungi under conditions of simultaneous temperature and salt stress, Int. Biodeterior. Biodegr., Vol. 56, pp: 197-205.

[17] Gunde-Cimerman, N. \& Zalar, P., (2014). Extremely halotolerant and halophilic fungi inhabit brine in solar salterns around the globe, Food Technol. Biotechnol., Vol. 52, pp: 170-179

[18] Mansour, M., (2017). Effects of the halophilic fungi Cladosporium sphaerospermum, Wallemia sebi, Aureobasidium pollutants and Aspergillus nidulans on halite formed on sandstone surface, Int. Biodeterior. Biodegrad., Vol.117, pp: 289-298.

[19] Srinivasan, R., Yandigeri, M., Kashyap, S. \& Alagawadi, A., (2012). Effect of salt on survival and P-solubilization potential of phosphate solubilizing microorganisms from salt affected soils, Saudi J. Biological Sciences., Vol.19, pp: 427-434.

[20] Rampelotto, P., (2013). Extremophiles and Extreme Environments, Life, Vol.3, pp: 482-485.

[21] Stevenson, A., Philip, G., Dijksterhuis, H. \& Hallsworth, J., (2017). Water-, $\mathrm{pH}-$ and temperature relations of germination for the extreme xerophiles Xeromyces bisporus (FRR 0025), Aspergillus penicillioides ( $\mathrm{JH}$ 06THJ) and Eurotium halophilicum (FRR 2471), Microbial Biotechnology, Vol.10, pp: 330-340. 
[22] Plavsi, D., Okanovic, D., Gubic, J. \& Njezic, Z., (2015) Microbiological and chemical evaluation of dried smoked meat product, Procedia Food Science. Vol. 5, pp: 239-242.

[23] Gock, M., Hocking, A. Pitt, J., Poulos, P., (2003). Influence of temperature, water activity and $\mathrm{pH}$ on growth of some xerophilic fungi, Int. J. Food Microbiol., Vol.81, pp: 11-19.

[24] Piñar, G., Piombino-Mascali, D., Maixner, F., Zink, A. \& Sterflinger, K., (2013). Microbial survey of the mummies from the capuchin catacombs of Palermo, Italy: Biodeterioration risk and contamination of the indoor air, FEMS Microbiol Ecol., Vol. 86(1), pp: 341-56.

[25] Sterflinger, K. \& Piñar, G., (2013). Microbial deterioration of cultural heritage and works of art--tilting at windmills?, Appl. Microbiol. Biotechnol., Vol. 97, pp: 9637-9646.

[26] Leitão, A., García-Estrada, C., Ullán, R., Guedes, S., Martín-Jiménez, P., Mendes, B. \& Martín, J., (2012). Penicillium chrysogenum var. halophenolicum, a new halotolerant strain with potential in the remediation of aromatic compounds in high salt environments, Microbiol. Research. Vol.167, pp: 79-89.

[27] Mossel, D., Corry, J, Struijk, C. \& Baird, R., (1996). Essentials of the microbiology of foods: A textbook for advanced studies, $1^{\text {st }}$ ed., Wiley, Chichester.

[28] Jay, M., Loessner, M. \& Golden, D., (2005). Modern food microbiology, Springer, NY.

[29] Baltic, M. \& Boskovic, M., (2015). When man met meat: Meat in human nutrition from ancient time still today, Procedia Food Sci., Vol. 5, pp: 6-9.

[30] Gutarowska, B., Pietrzak, K., Machnowski, W. \& Milczarek, J., (2017). Historical textiles - a review of microbial deterioration analysis and disinfection methods, J. Textile Research, Vol. 87, pp: 2388-2406

[31] Montegut, D., Indictor, N. \& Koestler, R., (1991). Fungal deterioration of cellulosic textiles: A review, Int.
Biodeterior. Vol. 28 (1-4), pp: 209226.

[32] Sequeira, S., Cabrita, E. \& Macedo, M., (2012). Antifungals on paper conservation: An overview. Int. Biodeterior, Biodegrad., Vol.74, pp: 6786.

[33] Kavkler, K., Gunde-Cimerman, N., Zalar, P. \& Demsar, A., (2015). Fungal contamination of textile objects preserved in Slovene museums and religious institutions, Int. Biodeterior. Biodegrad., Vol.97, pp:51-59.

[34] Lech, T., Ziembinska-Buczynska, A. \& Krupa, N., (2015). Analysis of microflora present on historical textiles with the use of molecular techniques, Int. J. Conserv. Sci., Vol. 6, pp: 137-144.

[35] Montanari, M., Melloni, V., Pinzari, F. \& Innocenti, G., (2012). Fungal biodeterioration of historical library materials stored in compactus movable shelves, Int. Biodeterior. Biodegrad., Vol.75, pp: 83-88.

[36] Čavka, M., Glasnović, A., Janković, I., Sikanjić, P., Perić , B., Brkljacić, B., Mlinarić-Missoni, E. \& Skrlin, J., (2010). Microbiological analysis of a mummy from the archeological museum in Zagreb, Collegium Antropologicum., Vol.34, pp: 803-805.

[37] Sonjak, S., Licen, M., Frisvad, J. \& Gunde-Cimerman, N., (2010). The mycobiota of three dry-cured meat products from Slovenia, Food Microbio., Vol. 1, pp: 1-4.

[38] Škrinjar, M., Janković, V., Vesković-Moračanin, M. \& Vukojević, B., (2012). Xerophilicmoulds isolated from spices used in meat industry as potential producers of mycotoxins, Proc. Nat. Sci, Matica Srpska Novi Sad., Vol. 123, pp:7-16.

[39] Visagie, C.., Yilmaz, N., Renaud, J., Sumarah, M., Hubka, V., Firsvad, J., Chen, A., Meijer, M. \& Seifert, K., (2017). A survey of xerophilic Aspergillus from indoor environment, including descriptions of two new section Aspergillus species producing eurotium-like sexual states, Myco Keys, Vol.19, pp: 1-30. 
[40] Janda, K., Ulfig, K., Markowska, A., (2009). Extracellular enzyme profiles of xerophilic fungi isolated from dried materials of medicinal plants, Polish J. of Environ. Stud., Vol.18 (3), pp: 391-397

[41] Segal, L., Creely, J., Martin, A. \& Conrad, C., (1959). An empirical method for estimating the degree of crystallinity of native cellulose using the X-ray diffractometer, Textile Research Journal, Vol. 29, pp: 786-794.

[42] White, T., Bruns, T., Lee, S. \& Taylor, J., (1990). Amplification and direct sequencing of fungal ribosomal RNA genes for phylogenetics, In PCR Protocols: A Guide to Methods and Applications, Academic Press, NY, pp: 315-322.

[43] Vasanthakumar, A., De Araujo, A., Mazurek, J., Schilling, M. \& Mitchell, R., (2013). Microbiological survey for analysis of the brown spots on the walls of the tomb of King Tutankhamun, Int Biodet Biodegr., Vol.79, pp: 56-63.

[44] Miller, A., Laiz, L., Dionísio, A., Macedo M. \& Saiz-Jimenez, C., (2009). Growth of phototrophic biofilms from limestone monuments under laboratory conditions, Int. Biodeterior. Biodegr., Vol. 63, pp: 860-867.

[45] Danilatos, G. \& Robinson, V., (1979). Principles of scanning electron microscopy at high specimen pressures, Scanning.Vol.2, pp: 72-82.

[46] Mansour, M., Salem, M. \& Shoeib, A., (2015). Study the degradation of cellulosic fiber by four common fungi: Chromatic alterations and SEM examination. Center for the Global Study of Cultural Heritage and Culture, Kansai Univ., Vol. 3, pp: 99-110.

[47] Szopa, J., Wróbel, M., kowsk, W., Kulm, A., Katarzyna, M., Telichowskac, S., Dymińska, L., Mączkae, M., Hanuza, J., Zebrowsk, J. \& Pre- isne, M., (2009). Chemical composition and molecular structure of fibers from transgenic flax producing polyhydroxybutyrate, and mechanical properties and platelet aggregation of composite materials containing these fibers, Composites, Sci. Technol. Vol. 69, pp: 2438-2446.

[48] Mohapatra, H. \& Malik, R., (2015). Effect of microorganism on flax and linen, J. Textile Sci Eng., Vol. 6 (1), pp: 1:4

[49] Abdel-Maksoud, G., El-Amin, A., (2013). The investigation and conservation of a gazelle mummy from the Late Period in ancient Egypt, MAA. Vol.13 (1), pp: 45-67.

[50] Hassan, R. \& Mansour, M., (2018). A microscopic study of paper decayed by Trichoderma harzianum and Paecilomyces variotii, Journal of Polymers and the Environment, Vol. 26 (7), pp: 2698-2707.

[51] Betat, H., Rammelt, C. \& Mörl, M., (2010). tRNA nucleotidyl transferrases: Ancient catalysts with an unusual mechanism of polymerization, Cellular and Molecular Life Sciences, Vol. 67 (9), pp: 1447-1463.

[52] Liu, K., Porras-Alfaro, A., Kuske, C., Eichorst, S. \& Xie, G., (2012). Accurate, rapid taxonomic classifycation of fungal large-subunit rRNA genes, Appl Environ Microbiol., Vol. 78, pp: 1523-1533.

[53] Liu, Y-F., Gu, J-D. \& Mu, B-Z., (2017). Type II chaperonin gene as a complementary barcode for $16 \mathrm{~S}$ rRNA gene in study of Archaea diversity of petroleum reservoirs, Int. Biodeterior. Biodegrad., Vol. 123, pp: 113-120.

[54] Abdel-Hafez, S., Maubasher, A. \& Abdel-Fattah, H., (1978). Cellulosedecomposing fungi of salt marshes in Egypt, Folia Microbiologica, pp: 23:37.

[55] Vasanthakumar, A., DeAraujo, A., Mazurek, J., Schilling, M., Mitchell, R., (2015). Pyomelanin production in Penicillium chrysogenum is stim- 
ulated by L-tyrosine, Microbiology, Vol.161, pp: 1211-1218.

[56] Zalar, P., de Hoog, G. \& Schroers, H-J., (2007). Phylogeny and ecology of the ubiquitous saprobe Cladosporium sphaerospermum, with descriptions of seven new species from hypersaline environments, Studies in Mycology. Vol. 58, pp: 157-183.

[57] Siegel, S. \& Siegel, B., (1979). Growth of fungi in $\mathrm{NaCl}-\mathrm{MgSO}_{4}$ brines, Life Sci Space Res., Vol. 17, pp: 95-98.

[58] Niknejad, F., Moshfegh, M., Najafzadeh, M., Houbraken, J., Rezaei, S.,
Zarrini, G., Faramarzi, M. \& NafissiVarcheh, N., (2013). Halotolerant ability and $\alpha$-amylase activity of some saltwater fungal isolates, Iran J. Pharm Res., Vol. 12, pp: 113-119.

[59] Cotty, P., (1989). Virulence and cultural characteristics of two Aspergillus flavus strains pathogenic on cotton, Phytopathology. Vol.79, pp: 808-814.

[60] Alapont, C., Martínez-Culebras, P., López-Mendoza, M., (2015). Determination of lipolytic and proteolytic activities of mycoflora isolated from dry-cured teruelham, J. FoodSci Technol., Vol. 52, pp: 5250-5256. 